\title{
INVENTÁRIO DA ARBORIZAÇÃO EM DUAS VIAS DE MARIÓPOLIS/PR
}

\author{
Lenir Maristela Silva ${ }^{1}$; Ionete Hasse ${ }^{2}$; Danielle Acco Cadorin ${ }^{3}$; Kleber Andolfato de Oliveira ${ }^{4}$; \\ Flávio Augusto Cella de Oliveira ${ }^{5}$; Celso Ferraz Bett ${ }^{6}$
}

(recebido em 23.08.2007 e aceito pra publicação em 06.03.2008)

\section{RESUMO}

Foram analisadas as condições da arborização da Avenida Brasil e da Rua Hum de Mariópolis-PR. Os parâmetros para coleta de dados constaram da identificação da espécie; altura; situação da raiz; altura da primeira bifurcação; área livre; larguras de ruas e calçadas; tipo de poda; dados relativos à integridade e relação da arborização com placas de sinalização e fiação elétrica. Foram analisadas 424 árvores, pertencentes a 20 espécies. A espécie mais abundante o ligustro (Ligustrum lucidum - 54\%) é exótica, o que caracteriza falta de identidade com o bioma local (Floresta com Araucária). Das espécies encontradas, doze são exóticas, oito são nativas do Brasil, dessas últimas apenas três são do bioma local. Seis espécies encontram-se na lista oficial de invasoras do estado do Paraná. As características viárias das ruas investigadas são favoráveis à arborização, contudo, o manejo não é adequado. A maioria das áreas livres foi inferior a $1 \mathrm{~m}^{2}$ e a inserção da primeira bifurcação das espécies encontrava-se inferior a 1,80 $\mathrm{m}$ na maior parte dos indivíduos. Observou-se calçadas com levantamentos e rachaduras causadas, principalmente, por espécies de grande porte com pouca área livre (Ligustro e Tipuana Tipuana tipu) e também o uso de espécie inadequada no canteiro central sob fiação (Ligustro).

Palavras-chave: Ligustrum lucidum; espécies invasoras; censo.

\footnotetext{
1 . Doutora em Produção Vegetal, UTFPR, Pato Branco/PR, lenir@utfpr.edu.br

2 . Doutora em Produção Vegetal, UTFPR, Pato Branco/PR, hasse@utfpr.edu.br

3 . Acadêmica do Curso de Agronomia, UTFPR, Pato Branco/PR, danikadorin@hotmail.com

4. Acadêmico do Curso de Agronomia, UTFPR, Pato Branco/PR, kleberandolfato@yahoo.com.br

5 . Acadêmico do Curso de Agronomia, UTFPR, Pato Branco/PR, f99115242@yahoo.com.br

6 . Acadêmico do Curso de Agronomia, UTFPR, Pato Branco/PR, celsinho.skt@gmail.com
} 


\title{
INVENTORY OF URBAN TREES IN MARIÓPOLIS - PR
}

\begin{abstract}
The conditions of arborization of Brasil Avenue and Hum Street in Mariópolis were analyzed. The parameters for data collection included the identification of the species; height; situation of the root; height of the first bifurcation; free area; width of streets and sidewalks; type of pruning; data relative to integrity and relation of arborization with traffic signs and electric wires. Four hundred twenty-four trees were analyzed, belonging to twenty species. The most abundant species (Ligustrum lucidum - 54\%) is exotic, what characterizes lack of identity with the local biome (forest with 'Araucária'). From the species found, twelve are exotic, eight are native of Brazil, and, from these last ones, only three are from the local biome. Six species are in the official list of invaders of the State of Paraná. The traffic characteristics of the investigated streets are favorable to arborization, but the handling is not adequate. The majority of free areas was inferior to $1 \mathrm{~m} 2$ and the insertion of the first bifurcation of the species was inferior to $1,80 \mathrm{~m}$ at the majority. It was observed sidewalks with uplifts and cracks caused, mainly, by big sized species with little free area (Ligustro and Tipuana Tipuana tipu) and also the use of inadequate species in the central bed of flowers under the electric wires (Ligustro).
\end{abstract}

Key-words: Ligustrum lucidum; invader species; census. 


\section{INTRODUÇÃO}

As árvores urbanas trazem muitos benefícios para os habitantes das cidades: reduzem o calor e a poluição atmosférica e sonora; diminuem a velocidade dos ventos; produzem sombra; captam e drenam água evitando enchentes, contribuem para a formação das nuvens; embelezam ruas, canteiros, praças e jardins; protegem o solo; e atraem a avifauna, dentre outros benefícios. Por esta razão, atualmente, tem sido mais valorizada à prática da arborização urbana.

Nos planejamentos da arborização é indispensável à precedência de inventário. Os inventários consistem na coleta de dados da área viária e dos espécimes arbóreos. Langowski e Klechowicz (2001) ressaltam que além dos fatores físicos da planta é importante analisar o local em que a mesma será implantada, uma vez que as condições físicas e químicas do local de plantio são determinantes no desenvolvimento das árvores. Dentre as cidades brasileiras que inventariaram parte da arborização urbana destacam-se: Piracicaba-SP, Campina Grande-PB, Curitiba-PR, Santos-SP, Campos do Jordão-SP, Nova Iguaçu-RJ, Horizontina-RS e Pato Branco-PR (MILANO, 1985; ANDRADE, 2002; DANTAS e SOUSA, 2004; FLORIANO, et al., 2004; ROCHA, LELES e NETO, 2004; COLTRI, et al., 2005; SILVA et al. 2007).

O município de Mariópolis foi colonizado a partir da década de 1940 sem planejamento paisagístico coerente para a cidade. Como conseqüência, houve muitos plantios aleatórios e com espécies inadequadas, como por exemplo, espécies de grande porte sob fiação elétrica. Por iniciativa da Prefeitura Municipal, em 2006 realizou-se um inventário de duas vias principais da cidade com o objetivo de diagnosticar e subsidiar o planejamento da melhoria da arborização urbana.

\section{METODOLOGIA}

A cidade de Mariópolis situa-se no sudoeste do Paraná, possui cerca de 6112 habitantes e apresenta uma área de $274,7 \mathrm{~km}^{2}$. Foram inventariadas duas áreas viárias localizadas em Mariópolis/PR, a Avenida Brasil e a Rua Hum, ambas impermeabilizadas com asfalto.

Essa região era originariamente coberta por Floresta Ombrófila Mista Montana (Floresta com Araucária), composição do bioma mata atlântica. Tal região estende-se pelo segundo e terceiro planaltos do estado do Paraná (NETO, 2006).

O clima do município é classificado como Cfa segundo Köppen, com temperaturas médias máximas acima de $22^{\circ} \mathrm{C}$ no verão e abaixo dos $18^{\circ} \mathrm{C}$ no inverno e precipitação 
anual média de 2.000 milímetros (RANDMANN, 2002). O solo da região é do tipo latossolo vermelho distroférrico (EMBRAPA, 1999).

Os parâmetros para a realização do inventário foram indicados em planilha e constavam da identificação da espécie pelo nome vulgar e pelo nome científico; altura; situação da raiz na relação com a calçada (causando ou não o levantamento ou rachaduras na calçada); altura da primeira bifurcação; área livre do entorno da árvore (pequena: menor que $1 \mathrm{~m}^{2}$; boa: igual ou maior que $1 \mathrm{~m}^{2}$ ); larguras de ruas e calçadas; outros dados relativos à integridade (pragas, doenças e danos mecânicos) e relação da arborização com placas de sinalização e fiação elétrica. Quanto à poda foram utilizados os seguintes critérios: sem poda; necessitando de poda; poda drástica (quando o espécime apresentava: remoção total da copa, permanecendo acima do tronco os ramos principais com menos de um metro de comprimento nas árvores adultas; remoção total de um ou mais ramos principais; remoção total da copa de árvores jovens e adultas, resultando apenas o tronco); poda de segurança (alguns galhos retirados por medida de segurança).

A freqüência relativa de cada espécie foi calculada pela razão entre o número de indivíduos da espécie e o número total de espécimes, multiplicada por 100.

\section{RESULTADOS E DISCUSSÃO}

Foram analisados 424 indivíduos arbóreos pertencentes a 20 espécies diferentes (Tabela 01). 
Tabela 01 - Freqüência das espécies presentes na arborização da avenida Brasil e rua hum de Mariópolis/PR/2006.

\begin{tabular}{|c|c|c|c|}
\hline Nome comum & Nome científico & Origem & Freqüência \\
\hline Ameixa & Eriobotrya japonica (Thunb.) Lindl. & Ásia & $0,24 \%$ \\
\hline Aroeira & ${ }^{*}$ Schinus molle L. & Brasil & $15,80 \%$ \\
\hline Cássia & Cassia leptophylla Vogel & Brasil & $0,24 \%$ \\
\hline Casuarina & Casuarina equisetifolia. L. & Austrália & $4,95 \%$ \\
\hline Cedro & Cedrella fissilis $\mathrm{L}$. & Brasil & $0,24 \%$ \\
\hline Cinamomo & Melia azedarach L. & Ásia & $0,47 \%$ \\
\hline Cipreste & Cupressus Iusitanica Mill. & América Central & $1,65 \%$ \\
\hline Citrus & Citrus sp. L. & Ásia & $0,24 \%$ \\
\hline Erva Mate & *llex paraguariensis St. Hil. & Brasil & $0,94 \%$ \\
\hline Extremosa & Lagerstroemia indica $L$. & Ásia & $6,37 \%$ \\
\hline Grevilha & Grevillea robusta A. Cunn. Ex R. Br. & Austrália & $2,36 \%$ \\
\hline Ipês & $\begin{array}{c}\text { Tabebuia chrysotricha (Mart. Ex DC.) Standl. } \\
{ }^{*} \text { Tabebuia heptaphylla (Vell.) Tol. }\end{array}$ & Brasil & $0,94 \%$ \\
\hline Jerivá & Syagrus romanzoffiana (Cham) Becc & Brasil & $1,65 \%$ \\
\hline Ligustro & Ligustrum lucidum W.T. Aiton & Ásia & $54,01 \%$ \\
\hline Pinheiro-alemão & Cunninghamia lanceolata (Lamb.) Hooker f. & Ásia & $0,24 \%$ \\
\hline Pinus & Pinus sp. & América do norte e central & $0,47 \%$ \\
\hline Pitanga & ${ }^{\star}$ Eugenia uniflora L. & Brasil & $0,24 \%$ \\
\hline Tipuana & Tipuana tipu Benth. Kuntze & Argentina e Sul da Bolívia & $8,73 \%$ \\
\hline Uva Japão & Hovenia dulcis Thunb. & Ásia & $0,24 \%$ \\
\hline \multicolumn{3}{|c|}{$\begin{array}{l}\text { TOTAL } \\
\end{array}$} & $100 \%$ \\
\hline
\end{tabular}

* Obs: Espécies nativas da Floresta com araucária (BACKES e IRGANG, 2002; ISERNHAGEN, SILVA e GALVÃO, 2002)

Quatro das espécies mais abundantes (Fig. 01) são exóticas, não tendo nenhuma identidade com o bioma local. Dentre essas, a única espécie nativa do bioma é a aroeira mansa (Schinus molle). 


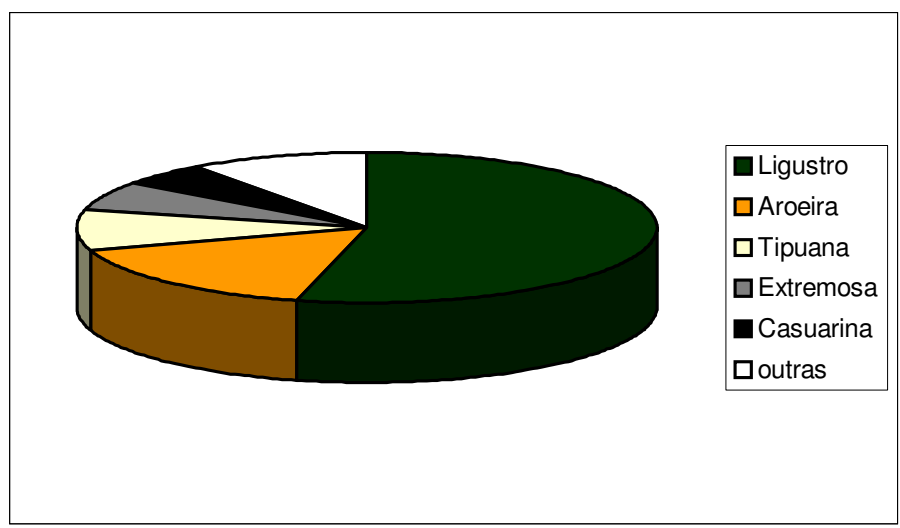

Figura 01 - Proporção de espécies mais abundantes na avenida Brasil e rua hum em Mariópolis/PR 2006.

A espécie mais abundante (54,01\%) Ligustrum lucidum (ligustro, alfeneiro) (Fig. 02) é muito comum nas cidades Sul-Brasileiras (BACKES e IRGANG, 2004). No Paraná essa espécie é invasora da Floresta Ombrófila Mista (INSTITUTO HÓRUS, 2005; IAP, 2007). Essa e outras espécies do gênero Ligustrum foram extensamente introduzidas com fins ornamentais e devido ao potencial invasor não devem mais ser utilizadas para este fim. As plantas existentes devem ser gradualmente substituídas por outras espécies (BRAND, 2005).

O canteiro central da Avenida Brasil que se encontra sob fiação elétrica, apresenta 84 espécimes, desses, 83 são ligustros. Portanto, além dos problemas ecológicos supramencionados dessa espécie, há o problema de ser de grande porte, não compatível com o canteiro central. Por isso, são visíveis as características que evidenciam várias podas drásticas já realizadas nos espécimes, como a presença de ramos epicórmicos.

Schinus molle L. (aroeira mansa) (Fig. 02) com a freqüência (15,80\%) é a única espécie nativa do Brasil e do bioma local, dentre as espécies mais abundantes na região inventariada. Santos e Teixeira (2001) alertam que esta espécie apresenta a ramificação muito pendente, o que pode atrapalhar a passagem dos pedestres pelo passeio. Esse problema pode ser evitado com a realização de podas de limpeza.

A terceira espécie em freqüência (8,73\%) a Tipuana tipu (tipuana) (Fig.02) é de grande porte, com ramos que formam enormes copas podem constituir túneis em ruas estreitas. Tem grande beleza ornamental. Os indivíduos dessa espécie já atingiram a maturidade e grande parte das calçadas no seu entorno encontram-se danificadas (Figura 03). Por isso, preferencialmente, essa espécie deve ser utilizada para ornamentar praças e jardins mas, pela alta capacidade de sombra e efeito paisagístico não se recomenda o corte quando já implantada, exceto quando esteja em risco, o que não é caso. 
Lagerstroemia indica L. (extremosa) (Fig. 02), que aparece na quarta colocação (6,37\%), por apresentar, quando adulta, de pequeno a médio portes, é, freqüentemente, recomendada para arborização urbana. Apesar dessa espécie não configurar na lista de espécies invasoras, ela apresenta restrições, principalmente, porque é muito suscetível a doenças (BIONDI e ALTHAUS, 2005).

A Casuarina equisetifolia (Fig. 02), em quinta colocação (4,95\%), faz parte de um grupo de árvores de grande porte, freqüentemente confundidas com Pinus. Essa espécie não é indicada para calçadas, pois não pode receber nenhum tipo de poda dada sua arquitetura monopodial. As podas podem deformar a arquitetura desse tipo de espécie, exceto que seja uma poda de limpeza que não interfira drasticamente na forma.

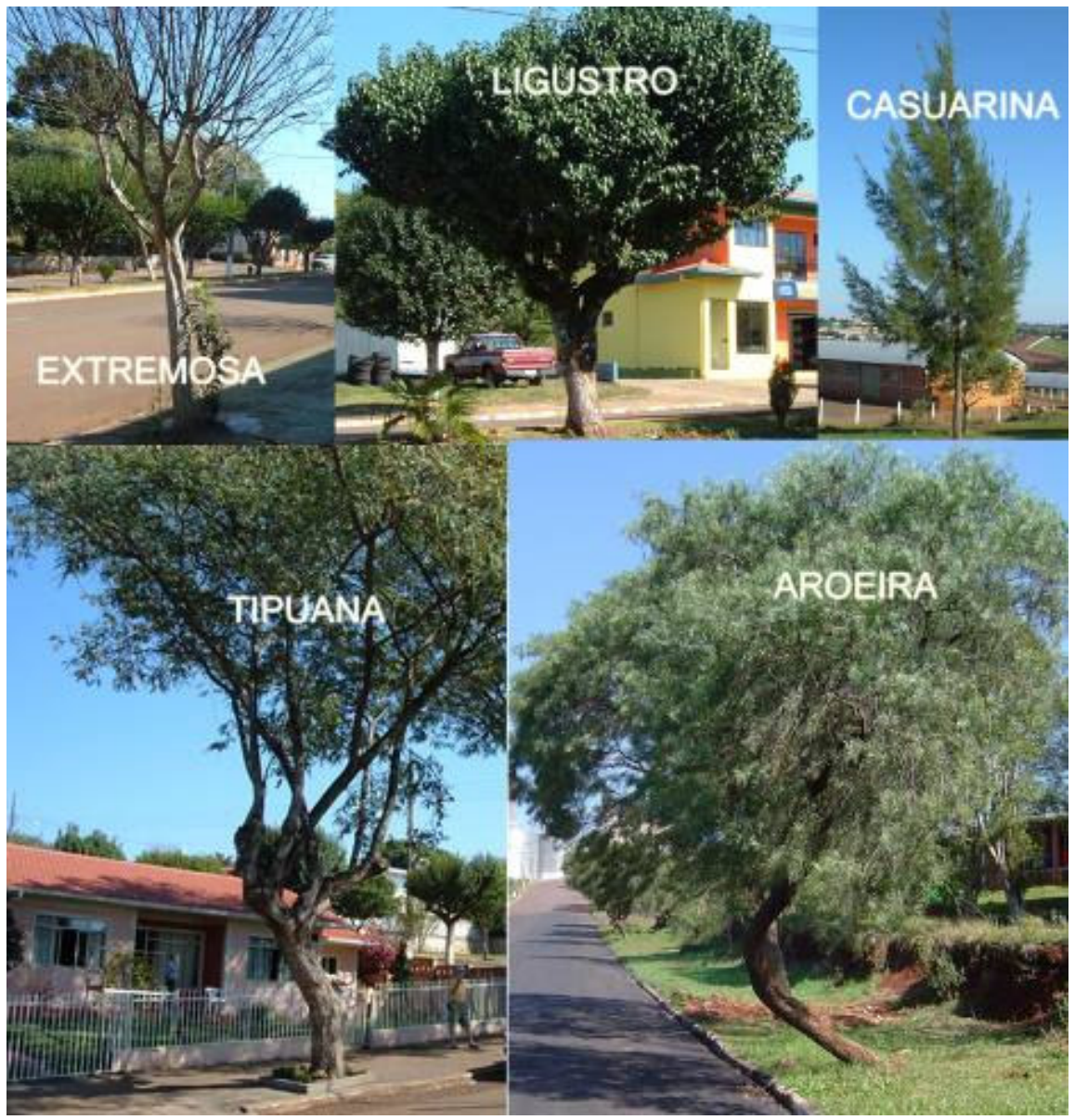

Figura 02 - Espécies mais abundantes na avenida Brasil e rua hum de Mariópolis/PR 2006

Das 20 espécies constantes na Tabela 01 apenas 08 são nativas do Brasil, sendo 03 nativas da Floresta com Araucária (Bioma local). São invasoras (tabela 01) do bioma local: Eriobotrya japonica, Melia azedarach, Ligustrum lucidum, Pinus sp, Casuarina equisetifoilia. e Hovenia dulcis (IAP, 2007). Essas espécies podem causar diversos danos ao ambiente, 
como a perda da biodiversidade, modificações dos ciclos e características naturais dos ecossistemas atingidos, alteração fisionômica da paisagem natural e, algumas vezes, conseqüências econômicas vultosas (ZILLER, 2001). Além disso, as espécies exóticas são mais facilmente exterminadas por doenças transmitidas por pragas e fitopatógenos.

Das árvores inventariadas 65\% apresentaram nenhuma ou pequena área livre (inferior a $1 \mathrm{~m}^{2}$ ) (Figura 03) dificultando a sobrevivência das espécies, pois uma árvore necessita de um espaço de crescimento tanto para a parte aérea, quanto para as raízes, bem como de área permeável para receber, ar, água e nutrientes (VELASCO, 2005).

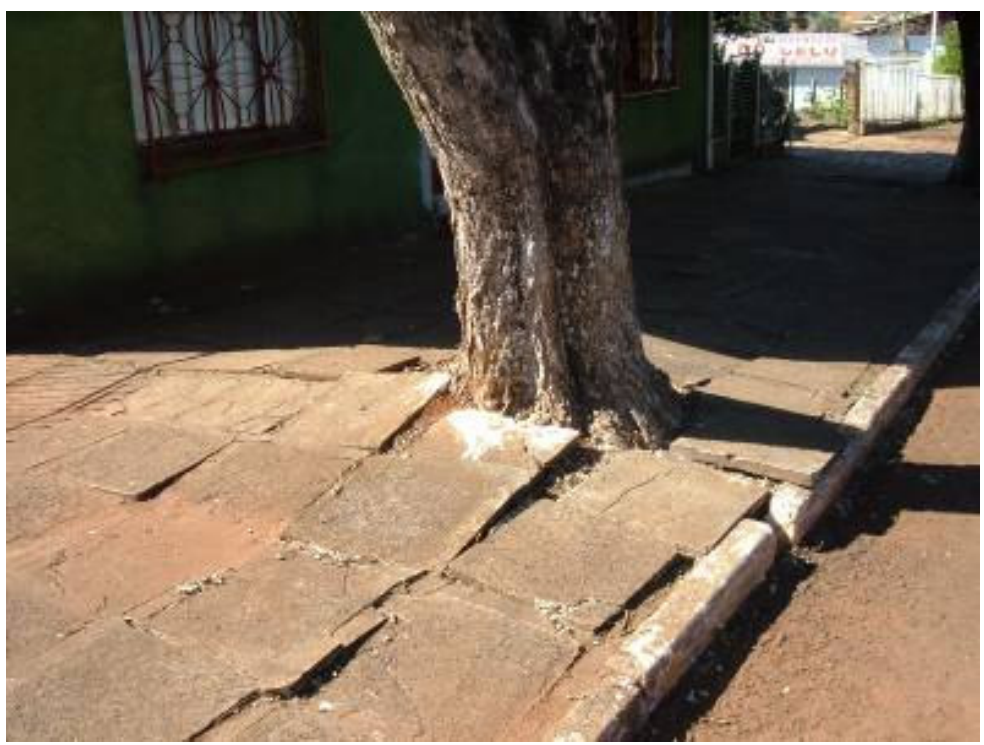

Figura 03 - Situação da área no entorno de uma tipuana na avenida Brasil de Mariópolis/PR 2006

As áreas permeáveis são, também, importantes para prevenir enchentes e o espaço livre de pavimento deve ser maior ou igual a $1 \mathrm{~m}^{2}$ (WYMAN, 1972, ANDRADE, 2002).

Para Miranda (1970), a inserção da primeira bifurcação deve ser de 2,00m, com algumas literaturas recomendando no mínimo $1,80 \mathrm{~m}$ para permitir o livre trânsito de pedestres na projeção da copa. No local inventariado a altura da primeira bifurcação, de muitos indivíduos arbóreos, estava abaixo de 1,80 m (Figura 04). 


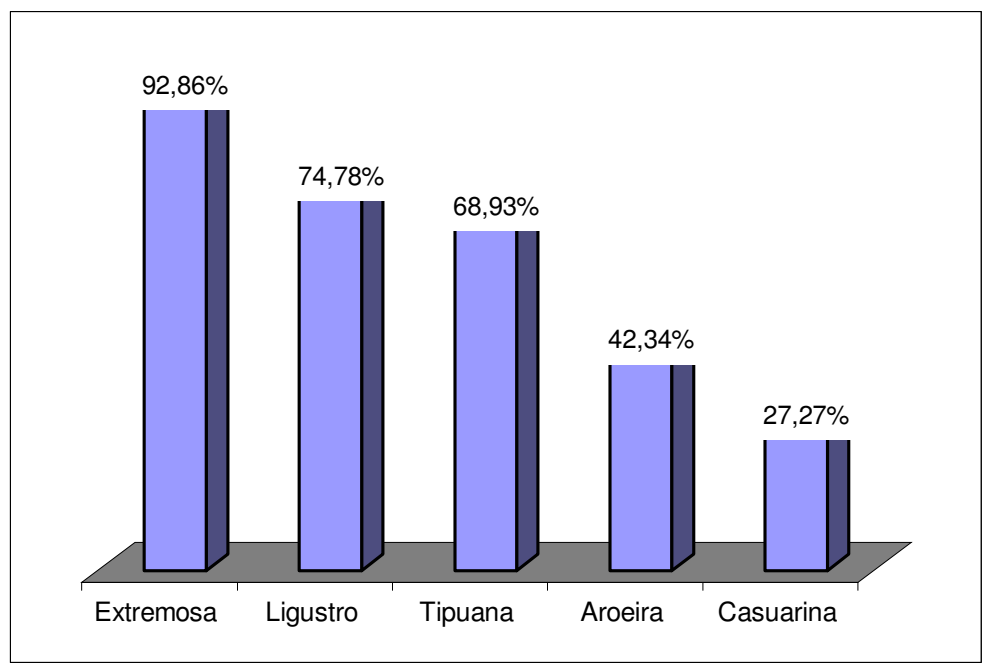

Figura 04 - 1a Bifurcação abaixo de 1,80m em espécies da avenida Brasil e rua Hum de Mariópolis/PR 2006.

A falta de poda de condução da muda é o principal motivo da bifurcação inferior ao recomendado. A poda, como tratamento na condução da muda no viveiro de espera, consiste na remoção de partes da planta, que comumente são brotações e galhos, mas também podem ser raízes e até mesmo flores e frutos. Em mudas, as podas fazem parte dos tratamentos aplicados para garantir plantas estruturalmente fortes e com menor necessidade de podas corretivas quando adultas (HARRIS, 1992).

Por isso, a recomendação de se plantarem mudas de no mínimo $1,80 \mathrm{~m}$ de altura, pois as suas ramificações ao se desenvolverem já estarão adequadas não acarretando problemas para a passagem dos pedestres e dos veículos (COELBA, 2002).

165 árvores encontravam-se em calçadas onde não há fiação e 259, sob a rede elétrica (tradicional). No quadro 01 destacam-se as alturas máximas das quatro espécies mais abundantes. A espécie que apresentou maior altura foi a Tipuana, cujos espécimes não se encontravam sob fiação.

\begin{tabular}{|c|c|}
\hline Espécie & Altura Máxima $(\mathbf{m})$ \\
\hline Tipuana & 17,0 \\
\hline Ligustro & 8,50 \\
\hline Aroeira & 7,60 \\
\hline Extremosa & 4,50 \\
\hline
\end{tabular}

Quadro 01 - Altura máxima por espécie arbórea presente na avenida Brasil e rua Hum em Mariópolis/PR 2006. 
Os fios, de alta tensão variam entre 9 a 12 m de altura (CEMIG, 2001), ou seja, a maioria das espécies não apresentou conflitos com a fiação, entretanto, podia-se perceber que alguns espécimes sofreram poda, inclusive, em alguns casos, poda drástica (Figura 05).

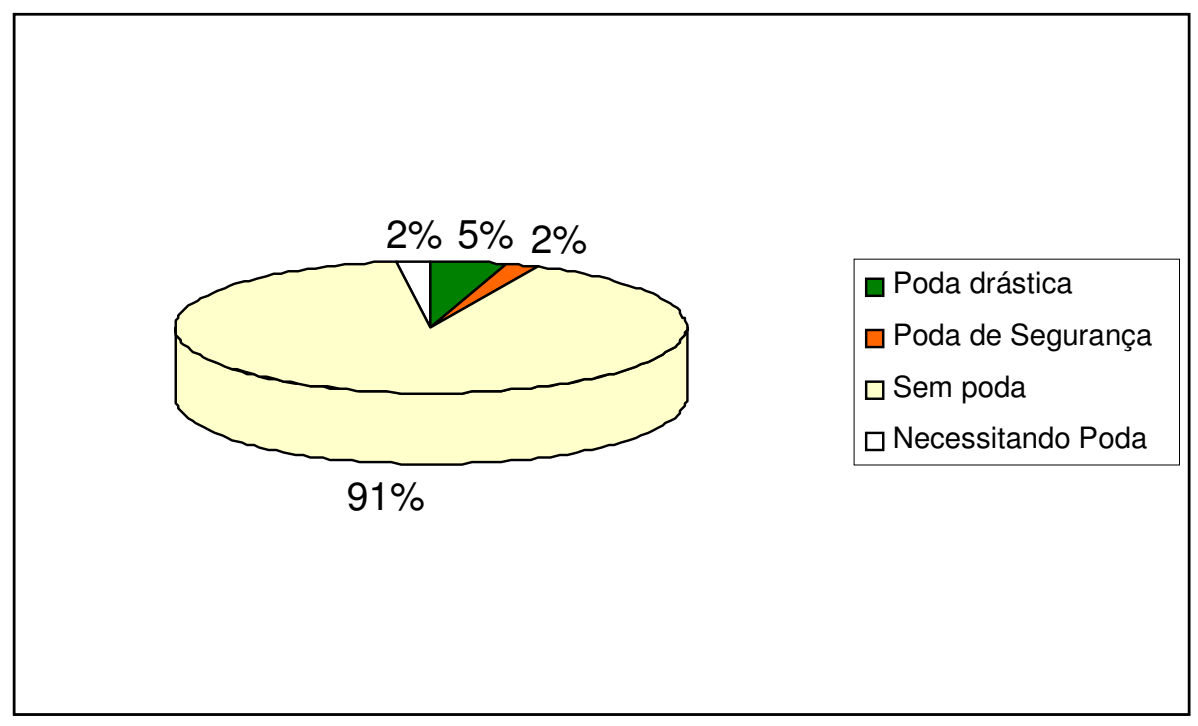

Figura 05 - Podas nos espécimes arbóreos na avenida Brasil e rua Hum em Mariópolis/PR 2006.

A poda drástica (LANGOWSKI e KLECHOWICZ, 2001) é uma verdadeira mutilação da árvore. Esse tipo de poda deve ser evitado, além de destruir o modelo arquitetônico original, provoca perda das raízes pequenas, aumento da espessura das raízes superficiais e o aparecimento de ramos epicórmicos que prejudicam o desenvolvimento da planta. Consequentemente pode haver redução do tempo de vida e até a morte do espécime.

A espécie que mais apresentou poda de segurança foi a Tipuana. Acredita-se que essa poda foi importante para manter os galhos longe da passagem de veículos, de residências e dos fios e é muito importante para espécies de grande porte, evitando-se assim a poda drástica.

Com relação aos danos causados as calçadas pelas raízes (Figuras 03 e 06) a Tipuana e o Ligustro foram às espécies que mais causaram levantamento e rachadura às calçadas. Ambas não são recomendadas em muitos guias de arborização justamente por esse prejuízo a área viária. As outras duas espécies (Aroeira e Extremosa) costumeiramente não agridem as calçadas com suas raízes, a agressão atual dessas espécies parece ter ocorrido pela restrição de área livre não permitindo que a raiz pudesse se expandir. 


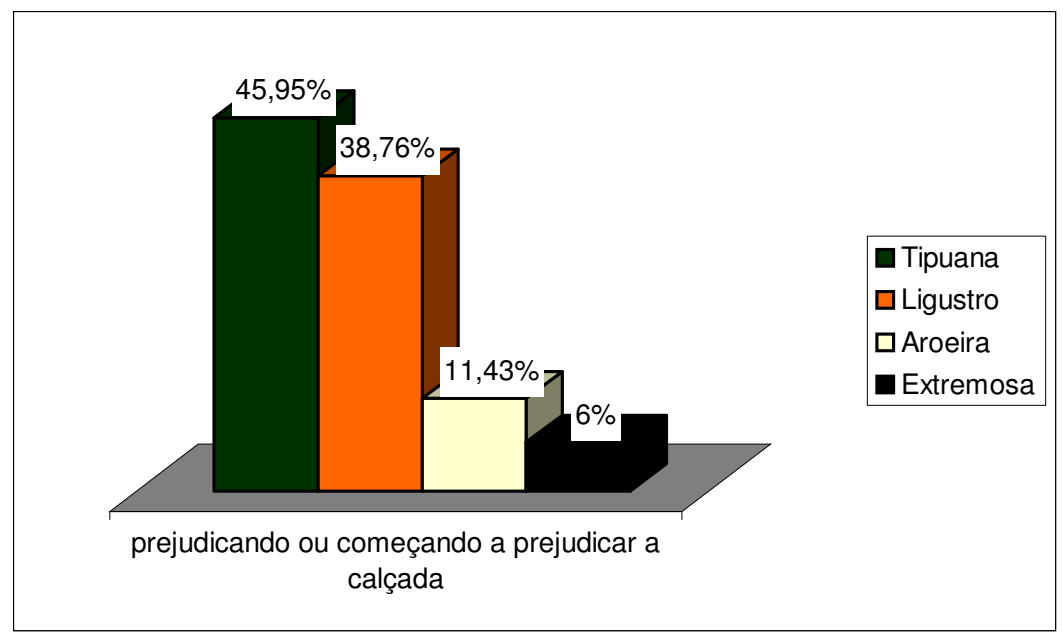

Figura 06 - Situação da raiz das quatro espécies mais abundantes na relação com as calçadas na avenida Brasil e rua Hum em Mariópolis/PR 2006.

As rachaduras e levantamentos de calçadas por árvores em área urbana (Figura 03) são problemas muito apontados na literatura, na maioria das vezes, ocorrendo por falta de manejo adequado como restrição da área livre ou também por uso de espécie inadequada para pavimentos.

Não foram identificadas ruas estreitas e a maioria das calçadas é larga, considerando ruas estreitas menores que sete metros e calçadas estreitas as menores que três metros. Além disso, há muitos pontos da área viária que ainda não possuem calçadas.

\begin{tabular}{|c|c|c|}
\hline \multicolumn{2}{|c|}{ Calçada (m) } & Rua (m) \\
\hline $\begin{array}{c}\text { Avenida Brasil/Acesso } \\
\text { Principal }\end{array}$ & 4,15 & 11,40 \\
\hline Rua Hum & 2,98 & 12,10 \\
\hline Avenida Brasil/Centro & 3,61 & \multirow{2}{*}{9,55} \\
\hline Canteiro Central & 3,74 & \\
& & \\
\hline
\end{tabular}

Quadro 02 - Dimensões médias das ruas e calçadas em Mariópolis/PR 2006.

As espécies de portes pequeno e médio podem ser colocadas em calçadas largas (superior a 2,0 m). Calçadas estreitas e ruas largas, em áreas residenciais, devem ser arborizadas nos lados sem fiação utilizando-se o plantio de espécies de pequeno e médio 
porte. Calçadas largas e ruas largas, sem a presença de fiação permitem espécies de porte médio (CEMIG, 2001).

As ruas amostradas em Mariópolis são largas e as calçadas possuem entre 2,98 m e 4,15 m de largura, o que facilita a implantação e desenvolvimento da arborização (Quadro 02).

Outros problemas visualizados foram: diversidade de espécies na mesma quadra, contaminação por cupim, contaminação por cochonilhas, calagem dos troncos, conflitos com placas de sinalização e vandalismo.

A diversidade de espécies numa mesma quadra não é recomendada, principalmente porque dificulta o manejo, além de não caracterizar a paisagem gerando uma confusão visual (SANTOS, 1994). Espécies diferentes têm comportamentos diferentes o que não recomenda a diversificação da arborização nas quadras. Há autores que sugerem que cada rua tenha uma dada espécie e outros que sugerem que pelo menos cada quadra tenha a mesma espécie. Outros ainda sugerem que podem ser colocadas espécies diferentes, contudo em cada lado da rua deve prevalecer a mesma (COELBA, 2002).

Os cupins Cornitermes sp foram encontrados nos Ligustros (Figura 07). Esses insetos (pragas) foram os mais detectados em dois bairros de Americana/SP e, as espécies arbóreas mais abundantes foram: Murraya exotica, Ligustrum lucidum e Licania tomentosa (SILVA, 2005). Todas essas espécies são exóticas. No meio urbano a falta de diversidade de espécies e o manejo inadequado, especialmente a poda drástica, são as principais portas de entrada para os cupins.

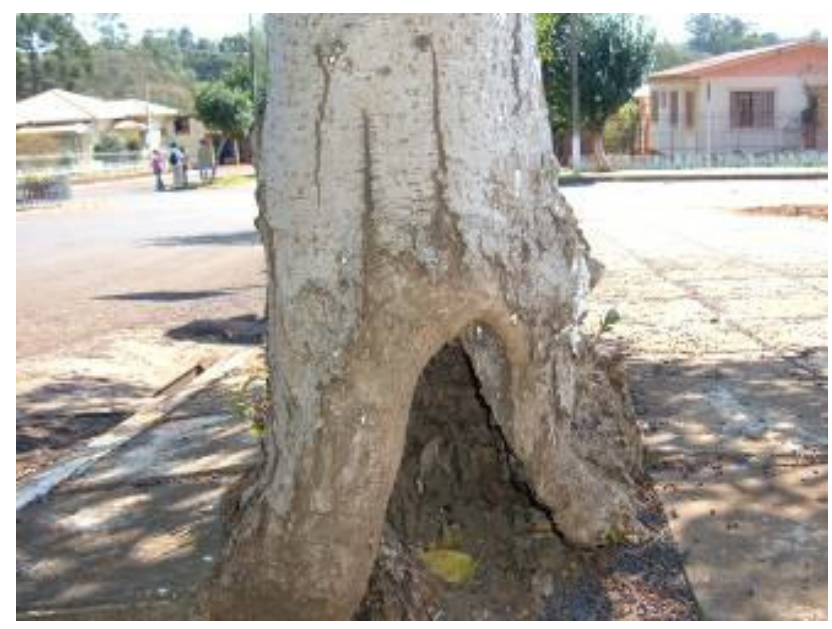

Figura 07 - Ligustro infestado por cupins na avenida Brasil em Mariópolis/PR 2006

As cochonilhas são insetos (homópteros) (Figura 08) considerados pragas por sugar a seiva da planta causando sérios danos. As plantas infestadas sofrem fitotoxicidade devido à injeção de enzimas digestivas, depositam excreções açucaradas nas folhas, resultando no 
aparecimento da fumagina e, às vezes, são responsáveis pela transmissão de agentes patogênicos (BOTTON, 2006). Nas situações de infestações elevadas do inseto em poucas árvores, como foi constatado (uma aroeira com alta infestação), o ideal é a limpeza da casca ou ainda a eliminação da planta pra evitar infestação em outras árvores. Em árvores urbanas é proibido o uso de qualquer agroquímico para controle de pragas e doenças.

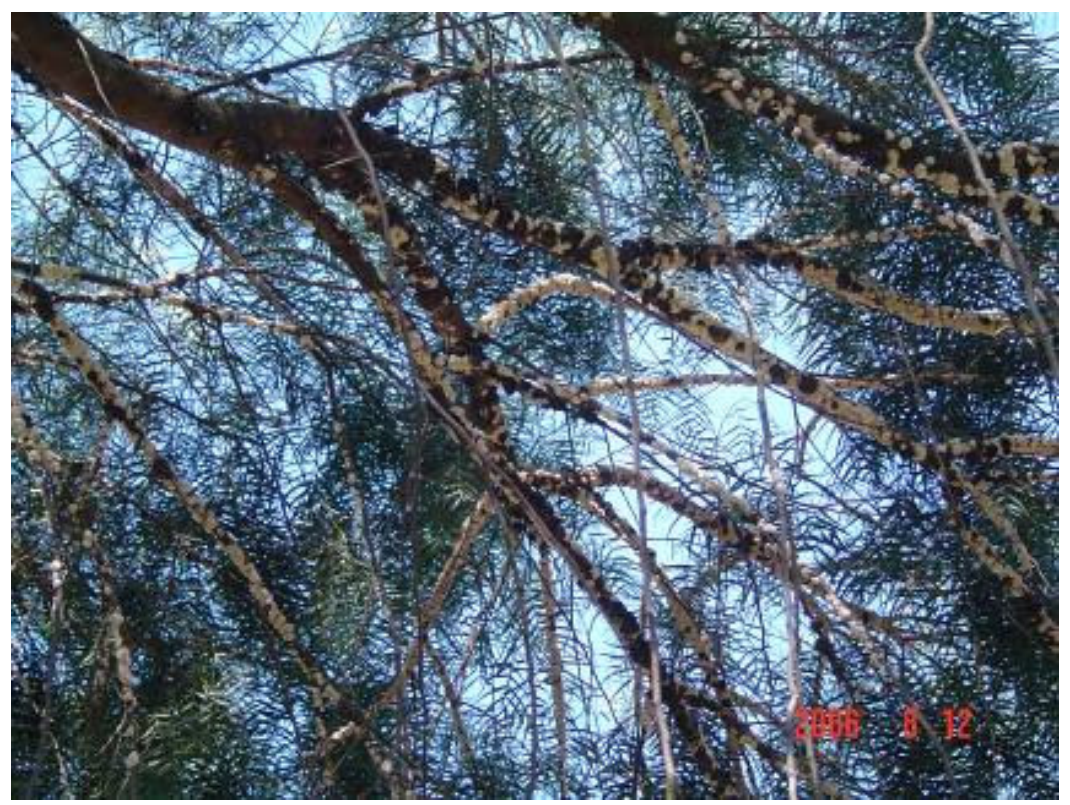

Figura 08 - Aroeira parasitada por cochonilhas na rua Hum em Mariópolis/PR 2006

A prática de pintura dos troncos com cal não é recomendada (SANTOS e TEIXEIRA, 2001). A cal esteriliza o tronco e evita o surgimento de organismos benéficos como os líquens que são ótimos indicadores de qualidade do ar. Em muitos municípios essa prática já é proibida por lei. Foi evidenciada a ausência de líquens em ligustros nos locais onde tinha sido aplicada a cal recentemente e também com aplicações de calagem anteriores (Figura 09). 


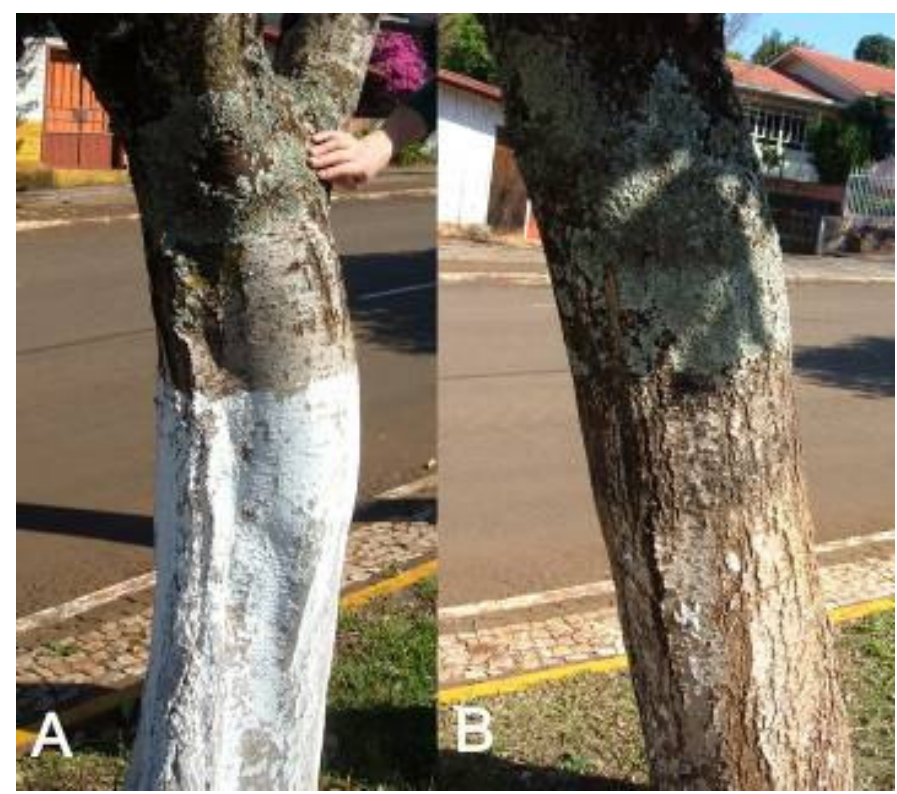

Figura 09 - A - ligustro com calagem recém aplicada; $\mathbf{b}$ - ligustro ainda sob efeito de uma aplicação de calagem anterior - na avenida Brasil em Mariópolis/PR 2006.

A arborização não deve atrapalhar a visibilidade da sinalização viária, portanto, deve-se evitar a colocação de placas próximo às árvores. É importante que o planejamento urbano leve em consideração a paisagem urbana para evitar transtornos como a poda drástica ou a retirada de uma árvore por conflitos com a sinalização. É evidente que estabelecido o problema deve-se proceder a poda de segurança eliminando dessa maneira, os galhos que estejam encobrindo a sinalização.

Ações de vandalismo só podem ser minimizadas com Educação Ambiental. Essa deve meta prioritária dos órgãos públicos, incluindo a educação formal e a informal como espaços para orientar e sensibilizar a população para cuidar e conservar a paisagem urbana.

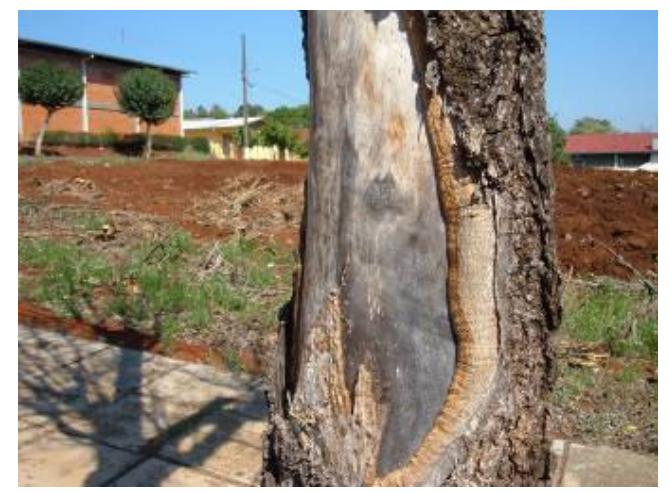

Figura 10 - Ipê roxo após ação de vandalismo na avenida Brasil em Mariópolis/PR 2006 


\section{CONCLUSÕES}

As avenidas principais de Mariópolis não apresentam uma identidade própria do bioma local com relação ao paisagismo, já que a espécie mais abundante (Ligustrum lucidum - 54\%) é exótica. Essa falta de identidade fica ainda mais evidente considerando o total de espécies encontradas, oito são nativas do Brasil, dessas apenas três do Bioma local e doze são exóticas. Dessas últimas, seis encontram-se na lista oficial de invasoras do estado do Paraná.

As características viárias das ruas investigadas são favoráveis à arborização, contudo, o manejo não é adequado, resultando nos diversos problemas apontados nesse estudo, como: a maioria das áreas livres do entorno das árvores foi inferior a $1 \mathrm{~m}^{2}$; a inserção da primeira bifurcação das espécies encontrava-se inferior a 1,80 m na maior parte dos indivíduos; calçadas com levantamentos e rachaduras causadas, principalmente, por espécies de grande porte com pouca área livre (Ligustro e Tipuana); e uso de espécie inadequada no canteiro central sobre fiação (Ligustro).

\section{REFERÊNCIAS}

ANDRADE, T. O. de. Inventário e análise da arborização viária da estância turística de Campos de Jordão, SP. São Paulo/SP, 2002. Dissertação. (Mestrado em Agronomia). ESALQ/USP - Escola Superior de Agricultura Luiz Queiroz, Universidade de São Paulo.

BACKES, P.; IRGANG, B. Árvores do sul: guia de identificação e interesse ecológico. Santa Cruz do Sul/RS: Instituto Souza Cruz, 2002. 325 p.

BACKES, P.; IRGANG, B. Árvores cultivadas no sul do Brasil: guia de identificação e interesse paisagístico das principais espécies exóticas. Porto Alegre: Palotti, 2004. 204 p.

BIONDI, D.; ALTHAUS, M. Árvores de rua de Curitiba: cultivo e manejo. Curitiba: FUPEF, 2005. 177 p.

BOTTON. M.;SORIA J. S.;HICKEL, R. E. Manejo de pragas na cultura da videira Cochonilhas.Disponível em: http://www.cnpuv.embrapa.br/publica/sprod/viticultura/cochoni.html. Acesso em 20/09/2006.

CEMIG - COMPANHIA ENERGÉTICA DE MINAS GERAIS. Manual de Arborização. Belo Horizonte: 2001. 
COELBA - Companhia de Eletricidade do estado da Bahia/Diretoria de Gestão de Ativos/Departamento de Planejamento dos Investimentos/ Unidade Meio Ambiente. Guia de Arborização Urbana. Salvador: Venturie Gráfica e Editora, 2002. 55p.

COLTRI, P.P.; VELASCO, G. D. N.; BARBIN, H. S.; POLIZEL, J. L. Arborização viária do centro de Piracicaba-SP e temperatura local: levantamento de dados e análise de imagens de satélite. In: IX CONGRESSO BRASILEIRO DE ARBORIZAÇÃO URBANA, Belo Horizonte. Anais...Belo Horizonte: SBAU, 2005, (CD-ROM).

DANTAS, I. C.; SOUZA, C. M. C. Arborização urbana na cidade de Campina Grande - PB: Inventário e suas espécies. Revista de Biologia e Ciências da Terra. vol. 4, n.02, 2004.

EMBRAPA - EMPRESA BRASILEIRA DE PESQUISA AGROPECUÁRIA - Centro Nacional de Pesquisa de Solos. Sistema Brasileiro de Classificação de Solos. Brasília: EMBRAPA, 1999.

FLORIANO, E. P. et al. Censo da arborização da região central da cidade de Horizontina, RS. Trabalho Técnico-científico n. 2, / Eduardo Pagel Floriano, Cibele Rosa Gracioli, Amarílio Motta Floriano, Rosana Maria Motta Floriano. Santa Rosa: Anorgs/Prefeitura municipal de Horizontina, 2004. 69p.

BRAND, K. América do Sul invadida. São Paulo: GISP- Programa Global de Espécies Invasoras, 2005.

GOMES, R. T. Análise morfo-anatômica comparativa das lesões foliares causadas por vírus transmitidas por Brevipalpus em Hibiscus rosa-sinensis, Ligustrum lucidum e Solanum violaefolium. Anais... Disponível <http://www.usp.br/siicusp/12osiicusp/ficha1462.htm> Acesso em 04/05/2006.

HARRIS, R. W. Arboriculture: integrated management of landscape trees, shrubs and vines. 2. ed. New Jersey: Prentice Hall, 1992. 674 p.

IAP - Instituto Ambiental do Paraná. Portaria IAP no 095, de 22 de maio de 2007. Disponível em www.pr.gov.br/meioambiente/iap/pdf/port_95_07.pdf> Acesso em 20 de junho de 2007. 
IBGE - INSTITUTO BRASILEIRO DE GEOGRAFIA E ESTATÍSTICA. Manual técnico da vegetação brasileira. Rio de Janeiro: IBGE, 1992. 92 p.

INSTITUTO HÓRUS DE DESENVOLVIMENTO E CONSERVAÇÃO AMBIENTAL /THE NATURE CONSERVANCY. Ligustrum lucidum. 2005. Disponível em http://www.institutohorus.org.br/download/fichas/Ligustrum_lucidum.htm>Acesso em 12/04/2006.

ISERNHAGEN, I; SILVA, S. M.; GALVÃO, F. Listagem de espécies arbustivo-arbóreas citadas nos trabalhos de fitossociologia florestal no Paraná, Brasil: uma contribuição aos programas de recuperação de áreas degradadas (RAD). In: A fitossociologia florestal no Paraná e os programas de recuperação de áreas degradadas: uma avaliação. Instituto de Pesquisa e Estudos Florestais - IPEF, 2002; Piracicaba, SP: Instituto de Pesquisas e Estudos Florestais. v.1, p. 51-134. Impresso.

LANGOWSKI, E; KLECHOWICH, N. Manual Prático de Poda e Arborização Urbana. Cianorte: APROMAC, 2001.

MILANO, M. S. Arborização de ruas de Curitiba/PR: uma análise qualitativa. In: ENCONTRO NACIONAL SOBRE ARBORIZAÇÃO URBANA, 1985. Porto Alegre. Anais...Porto Alegre: Scretaria do Meio Ambiente, 1985. p 83-86.

MIRANDA, M. A. Arborização de vias públicas. Campinas: Secretaria de Estado da Agricultura de São Paulo, Boletim Técnico SCR, 1970.

ROCHA, R. T.; LELES, P. S. S.; NETO, S. N. O. Arborização de vias públicas em Nova Iguaçu, RJ: o caso dos bairros Rancho Novo e Centro. Revista Árvore, Viçosa, v.28, n.4, p. 599-607, 2004.

NETO, J. D. C. Floresta Ombrófila Mista. 2006. Disponível em: http://www.wikipedia.org. Acesso em: 10/04/2007.

RANDMANN, S. P. Monitoramento e previsão do tempo no sudoeste do Paraná. 2002. Disponível em: http://www.simepar.br. Acesso em: 20/04/2007.

SANTOS, E. Caracterização dendrológica e estética de 128 espécies arbóreas com potencial de uso em paisagismo e arborização urbana. 1994. 146 p. Dissertação (Mestrado em Ciência Florestal). Universidade Federal de Viçosa, 1994. 
SANTOS, N. R. Z. dos; TEIXEIRA, I. F. Arborização de vias públicas: ambiente $x$ vegetação. Santa Cruz do Sul: Instituto Souza Cruz, 2001. 135p.

SILVA, L. F. da. Situação da arborização viária e propostas de espécies para os bairros Antônio Zanaga I e II da cidade de Americana/SP. 2005. 81 p. Dissertação - (Mestrado em Agronomia). Universidade de São Paulo - escola Superior de Agricultura Luiz Queiroz, 2005.

SILVA, L. M., HASSE, Ionete, MOCCELLIN, Renata, ZBORALSKI, Adriane Rodrigues. Arborização de vias públicas e a utilização de espécies exóticas: o caso do bairro Centro de Pato Branco/PR. Scientia Agraria (UFPR), v.8, p.91 - 97, 2007.

VELASCO, G. D. N.; LIMA, A. M. L. P. Danos em calçadas e sua relação com área permeável, circunferência à altura do peito (CAP) e poda em árvores urbanas. In: Congresso Brasileiro de Arborização Urbana 9, Anais... Belo Horizonte, 2005.

WYMAN, D. Parks, malls, roadsides: public area plantings, landscape for living. Washington: USDA. Forest Service, 1972. (Yearbook of agriculture).

ZILLER, S. R. Os processos de degradação ambiental originados por plantas invasoras. Revista Ciência Hoje. n. 178, dez. 2001. 